\title{
Effectiveness of Concept Map as Diabetic Foot Care Educational Intervention among Type 2 Diabetic Patients
}

\author{
Reem Mohammad AL Johani ${ }^{1}$, Aida Elgamil ${ }^{2}$, Elham Abduallah Al Nagshabandi ${ }^{3}$ \\ ${ }^{1}$ BSN, R.N, MSN, (Master Student) Nursing Faculty, University of King Abdul-Aziz, Jeddah, KSA. \\ ${ }^{2}$ Professor, Medical Surgical Nursing, Nursing Faculty, University of King Abdul-Aziz, Jeddah, KSA. \\ ${ }^{3}$ Associate Professor, Medical Surgical Nursing, Nursing Faculty, University of King Abdul-Aziz, Jeddah, KSA. \\ Reem-ALJohani-88@hotmail.com
}

\begin{abstract}
Background: Diabetes mellitus is affecting a huge percentage of the population in today's world. This disease is usually accompanied by the risk of development of foot complication that may lead to amputation of the foot. Therefore, diabetes mellitus patients are advised to ensure that they take proper care of their feet to avoid these complication.
\end{abstract}

Aim: This study aimed to determine the effectiveness of a concept map as diabetic foot care educational intervention among type 2 diabetic patients.

Methods: The research design adopted for the study was quasi-experimental with pre-test and post-test control groupdesign ${ }^{9}$. The study was conducted at outpatient department - Diabetic and Endocrine Centre in Al Madinah, Al-Munawara. Saudi Arabia after obtaining the Approval from Ethical Committee, and formal permission was obtained from the hospital authority. The samples were selected by convenient sampling technique, who met the inclusion criteria. The instrument used for the study was to collect the data are demographic variableFoot Care Confidence Scale (FCCS) and Nottingham Assessment of Functional Foot care (NAFF).

Results: The calculated Mean score of the foot care self-efficacy of the study group before concept map as intervention was 52.02 and it was significantly increased to 89.64 after concept map as educational intervention. In the control group mean score of before using concept map was 53.93 and in the after using concept map it was slightly increased to 58.23.The calculated Mean score of the foot care behaviour of the study group before using the concept map was 61.50 and it was significantly increased to 88.86 in after using the concept map. The calculated $\mathrm{p}$ value after intervention reveals that there was a significant difference between the study and control group at $(\mathrm{p}<0.001)$.There was a significant improvement in the foot care behaviour score in both groups after intervention $(\mathrm{p}<0.001)$.

Conclusion: Concept maps helps to identify some of the most effective strategies that can be used in the maintaining of healthy feet and preventing bruises and cuts and sores. Concept maps help nurses to improve in critical thinking in providing education on foot care and also advising patients on at-home foot care. This makes it easier for the patient and the practitioner to avoid any foot complications and ensure maintenance of healthy feet. Hence the study clearly depicts the importance of concept maps in educating patients with diabetes on importance of foot care.

Keywords: conceptmap, diabetic foot care, educational intervention, type 2 diabetic patients

\section{INTRODUCTION}

Chronic diseases have become a major public health problem and the leading cause of morbidity and mortality. The Saudi Arabian Ministryof Health reported that about 2.5 million people were diagnosed with diabetes in 2010 and the International Diabetes Federation reported that about 4 million people were diagnosed with 
Effectiveness of Concept Map as Diabetic Foot Care Educational Intervention among Type 2 Diabetic Patients

diabetes in Saudi Arabia in 2017 (International Diabetes Federation,2017). Also theWorld Health Organization reported that Saudi Arabia is the 2nd highest nation in the Middle East with an increasing rate of diabetes. Additionally, it takes the 7 th position for people affected by diabetes in the world ${ }^{1}$

Diabetes Mellitus are metabolic disorders characterized by elevated blood sugar levels which results into a variety of symptom and is primarily characterized by hyperglycaemia owing to imbalances in the secretion of insulin. Hyperglycaemia is linked to dysfunction and long-term damage to numerous body organs such as kidneys, blood vessels, eyes, heart, and nerves. Diabetes is currently on the rise worldwide and is associated with high mortality and morbidity rates. The World Health Organization reported that in 2015 stating that the number of diabetic patients is expected to rise to approximately 380 million by $2025^{1}$.If the condition is untreated over an extended period of time, it can lead to acute or serious long-term complications. Acute complications include hyperglycaemic state, diabetic ketoacidosis, hyperosmolar, or even death. Serious longterm complications include stroke, eye damage, cardiovascular disease, foot ulcers, and chronic kidney disease (WADA, 2015). Primarily, diabetes mellitus occurs due to the body's inability to secrete adequate insulin or respond properly to the insulin produced. Diabetes symptoms vary based on the type of diabetes a patient is diagnosed with. However, there are general symptoms of diabetic patients regardless of being a type 1, type 2 , or gestational diabetic patient. ${ }^{2}$

There are numerous causal factors of diabetes such as obesity, lack of physical activity, dietary factors increase the risk of developing diabetes such as foods with saturated fats and trans fatty acids and sugar-sweetened drinks. This type of diabetes is characterized by elevated glucose levels, increased production of fatty acids, and insulin deficiency ${ }^{3}$. Most type 2 diabetes patients are usually diagnosed years after the onset of the condition since most of its symptoms are disguisable or related to other conditions. Many studies have reported that, Type 2 diabetes is prevalent among adolescents. Pathophysiological changes arise from functional changes that result from injuries or particular diseases. ${ }^{4}$

Diabetic foot ulcers cause a lot of pathophysiological changes which can be in the form of atherosclerosis and peripheral neuropathy. Diabetic foot ulcers can result vascular disease effects as well as neuropathy. Generally diabetic patients are at a high likelihood of being infected with atherosclerosis, endothelial proliferation, arteriolar hyalinises and thickening of the basement of capillaries. Diabetic patients develop arthrosclerosis in their arteries characterized by large to medium size in the form of femoropopliteal and aortoiliac ${ }^{5}$. However, atherosclerosis in infrapopliteal is more common. If they combine with other arterial diseases ulcers can upgrade and proceed to gangrene if there is inadequate blood flow. Almost $60 \%$ of all diabetic patients are diagnosed with peripheral neuropathy while close to $80 \%$ develop foot ulcers. ${ }^{6}$

Patients diagnosed with diabetes mellitus should need to be educated on foot care to ensure self-care. Diabetic patients need to know the importance of foot care and to improves their foot condition and also prevents the development of foot complications among diabetic patients which has a significant impact on the individual and the economy ${ }^{7}$. Foot care involves several practices such as massaging one's feet, application of topical treatments, regular exercising, and purchasing over-the-counter medications for relieving foot pain. Therefore, it is essential to come up with an educational strategy such as concept maps to enhance self-foot care among diabetic patients. Concept maps make it easy for both health practitioners as well as patients ${ }^{8}$. With this background, the researcher interested to assess determines the effectiveness of a concept map as diabetic foot care educational intervention among type 2 diabetic patients.

\section{METHODS}

The research design adopted for the study was quasi-experimental with pre-test and post-test control group design ${ }^{9}$. The study was conducted at outpatient department - Diabetic and Endocrine Centre in Al Madinah, 
Effectiveness of Concept Map as Diabetic Foot Care Educational Intervention among Type 2 Diabetic Patients

Al-Munawara. Saudi Arabia after obtaining the Approval from Ethical Committee, and formal permission was obtained from the hospital authority. The samples were selected by convenient sampling technique who met the inclusion criteria, Adult patients who are diagnosed with type-2 Diabetes Mellitus, both male and female and willing to sign an informed consent and participate in the study were included in the study. Patients with other types of diabetes (Type I diabetes, Gestational diabetes) and patients with mental or intellectual impairments and unstable patients, were excluded from the study. The patients who consented in written form to participate were informed about the purpose of the study, rights to participate or withdraw from the study. The instrument used for the study was to collect the data are demographic variable and Foot Care Confidence Scale (FCCS) and Nottingham Assessment of Functional Foot care (NAFF).

\section{Demographic Variables}

Contained the information regarding as age, nationality, gender, marital status, level of education, occupation, and living place. It also includes the clinical variable such as family history of diabetes, duration of diabetes, teaches about foot care and follows up with podiatrist clinic.

\section{Foot Care Confidence Scale (FCCS)}

FCCS is an essential tool in measuring Foot-Care self-confidence. The survey instrument was translated into the local language (Arabic). The FCCS comprised of twelve questions which made use of five-point Likert scale with a score running from 1 to 5 with the scale , (strongly not confident $=1$, moderately not confident $=2$, confident $=3$, moderately confident $=4$, strongly confident $=5$ ). The minimum score as 12 and maximum score as 60 for all the 12 questions. TheLikert chart was useful in specifying the participant's level of agreement and disagreement based on their level of confidence in under the question at hand. The participants were expected to respond whether they either strongly not confident, moderately not confident, confident, moderately confident, or strongly confident. The maximum score of the FCCS was sixty, and high scores translated to high levels of selfefficacy beliefs.

\section{Nottingham Assessment of Functional Foot care (NAFF)}

NAFF is assessment tool for foot care behaviour in assessing the participants and comprised of 26 questions which generated a quantitative self-report measure involving persons with person compliance to foot care behaviour in line with healthcare practitioners which was translated to Arabic In line with the FCCS, the NAFF also used a Likert chart system with a range of 0-3 with the occurrence frequency of the behaviour. All the participants were to respond to the ranges which were 30ften, 2 Sometimes1 Rarely 0 Never. Moreover, the digit 3 also indicated doing the action more than once in a day, 2 represented once in a day, I represented more days in a week, 0 also indicated a few days in a week. The participants were requested to answer by themselves and the researcher helped to fill the survey instruments. The score was interpreted as $<50-$ Poor,50- $<75-$ Fair, $\leq$ 75-Good. They were assured about their confidentiality and anonymity throughout the study.

\section{Data Collection Procedure}

The importance of the study was explained to the authorities of the hospitals and obtained permission to conduct the study. The research purpose was explained to the patients and obtained oral and written consent. The demographic data was collected from the study participants on interview method for the both the study and control group and assessed the knowledge about the foot care self-efficacy behaviour using the survey questionnaire and Education of the diabetic and caring of foot was explained through the concept Mapping Education of the correct management of the diabetic was explained to the study group participants. Thus the data was collection procedure was carried out. 
Effectiveness of Concept Map as Diabetic Foot Care Educational Intervention among Type 2 Diabetic Patients

\section{Statistical Methods}

The data and statistical analysis was performed using Statistical Package for Social science (SPSS)version 22 for windows 10.Analysis was done to find out the significantly difference between the study and control groups regarding these variables. Descriptive data were described using number and present. Significance of the obtained results was judged at the $5 \%$ level. The used test Chi-square test: For categorical variables, to compare between different groups and Fisher s Exact or Monte Carlo correction: Correction for chi-square when more than $20 \%$ of the cells have expected count less than 5 .

\section{RESULTS}

\section{Table 1}

The present study findings showed the distribution of socio demographic characteristics for the study and control group. There were a total of 70 diabetes patients included in this study and they were divided into two equal group 35 diabetes patients in the study group and 35 diabetes patients in control group. The socio-demographic data shows that the "age of the respondents" the lowest percentage from the study group is (8.6\%) and the control group is $(2.9 \%)$ for individuals below the age of 30 years. The highest percentage from the study group above 50 years is (37.1\%) and those form control group above 50 years are (45.7\%). The "nationality" shows that $(94.3 \%)$ respondents of the study group are Saudi and (5.7\%) are Non-Saudi whereas $(97.1 \%)$ respondents of the control group are Saudi and (2.9\%) are Non-Saudi. The "gender" shows that (34.3\%) respondents of the study group are male and $(65.7 \%)$ are female whereas (45.7\%) respondents of the control group are male and (54.3\%) are female. Regarding the "marital status" shows that amongst respondents of study group (82.9\%) are single, $(5.7 \%)$ are married, $(2.9 \%)$ are divorced and $(8.6 \%)$ are widow whereas respondents of control group are (88.6\%) are single, (5.7\%) are married, (5.7\%) are divorced. In relation to "educational level" the highest percentage can read and write, (37.1) in the study group while only (14.3) were illiterate. Regarding the "occupation" shows that amongst respondents of study group (31.4\%) are administrative, (5.7\%) have elementary occupations, (57.1\%) unemployed and (5.7\%) retired whereas respondents of the control group (22.9\%) are administrative, (2.9\%) have elementary occupations, $(5.7 \%)$ clerical support worker, $(62.9 \%)$ unemployed and (5.7\%) retired. The "living place" shows that (25.7\%) respondents of study group belong to the rural population and $(74.3 \%)$ belong to urban population whereas (17.1\%) respondents of control group belong to the rural population and $(82.9 \%)$ belong to the urban population.

In the present study, clinical variables were observed and presented .The individuals with "family history of DM" shows that (85.7\%) respondents of study group said yes and $(14.3 \%)$ said no whereas $(91.4 \%)$ respondents of control group said yes and (8.6\%) said no. Regarding with the duration of Diabetes which they had; $40 \%$ individuals had less than 5 years and $5.7 \%$ individuals had diabetes for more than 20 years and over. In relation to "their follow-up with podiatrist clinic" in which study group highest percentage responded (91.4\%) responded no and lowest percentage responded (8.6\%) responded yes whereas in control group highest percentage responded (97.1\%) responded no and lowest percentage responded (2.9\%) responded yes. With regard to "how often they follow-up with podiatrist clinic" in which study group highest percentage responded (91.4\%) responded never and lowest percentage responded (2.9\%) responded once a month whereas in control group highest percentage responded $(97.1 \%)$ responded never and lowest percentage responded $(2.9 \%)$ responded once a year. Regarding the "receive health education about foot care" in which study group highest percentage responded (85.7\%) responded no and lowest percentage responded (14.3\%) responded yes whereas in control group highest percentage responded (94.3\%) responded no and lowest percentage responded (5.7\%) responded

yes. In relation with "teaches you about foot care" in which study group the highest percentage responded 
Effectiveness of Concept Map as Diabetic Foot Care Educational Intervention among Type 2 Diabetic Patients

(40\%) that foot care education was provided to them by the nurses and highest percentage responded (50\%) that doctors and diabetic education nurses provided foot care.

\section{Table 2}

In the present study the Mean of the foot care self -efficacy scale score of the study and control group before and after concept map as educational intervention. The score was interpreted by using the student $t$ test. The calculated Mean score of the foot care self-efficacy of the study group before concept map as intervention was 52.02 and it was significantly increased to 89.64 after concept map as educational intervention. In the control group mean score of before using concept map was 53.93 and in the after using concept map it was slightly increased to 58.23. The calculated $\mathrm{p}$ value for the difference in foot care self-efficacy scale score between the study and control group in before intervention was $(\mathrm{p}=0.752)$ and shows that there was no significant difference in the foot care self-efficacy score in the before intervention of the both groups. The calculated $\mathrm{p}$ value after intervention revealed that there was a significant difference between the study and control group at $(\mathrm{p}<0.001)$. There was a significant improvement in the foot care self-efficacy score in both the groups after intervention $(\mathrm{p}<0.001)$. Hence it can be concluded that there was significant statistical improvement in the study group was high after using the concept map as educational intervention.

\section{Table 3}

The present study revealed the Mean of the foot care behavior score of the study and control group before and after concept map as educational intervention. The calculated Mean score of the foot care behavior of the study group before using the concept map was 61.50 and it was significantly increased to 88.86 in after using the concept map. In the control group mean score of before intervention was 60.81 and in after intervention it was slightly increased to 64.21. The calculated $\mathrm{p}$ value for the difference in foot care behavior score between the study and control group in before intervention was $(\mathrm{p}=0.848)$ and shows that there was no significant difference in the foot care behavior score before intervention of the both groups. The calculated $p$ value after intervention reveals that there was a significant difference between the study and control group at $(\mathrm{p}<0.001)$. There was a significant improvement in the foot care behavior score in both groups after intervention $(p<0.001)$. Hence it can be concluded that there was high significant statistical improvement in the study group after using the concept map as educational intervention.

Table1. Distribution of Socio demographic characteristics for the study and control groups ( $n=70$ )

\begin{tabular}{|c|c|c|c|c|c|c|}
\hline \multirow{2}{*}{ Socio demographic data } & \multicolumn{2}{|c|}{ Study $(n=35)$} & \multicolumn{2}{|c|}{ Control $(n=35)$} & \multirow{2}{*}{$\chi^{2}$} & \multirow{2}{*}{$\mathbf{p}$} \\
\hline & No. & $\%$ & No. & $\%$ & & \\
\hline \multicolumn{7}{|l|}{ Age (years) } \\
\hline$<30$ & 3 & 8.6 & 1 & 2.9 & \multirow{4}{*}{1.536} & \multirow{4}{*}{${ }^{\mathrm{MC}} \mathrm{p}=0.706$} \\
\hline $30<40$ & 6 & 17.1 & 7 & 20.0 & & \\
\hline $40<50$ & 13 & 37.1 & 11 & 31.4 & & \\
\hline$\geq 50$ & 13 & 37.1 & 16 & 45.7 & & \\
\hline \multicolumn{7}{|l|}{ Nationality } \\
\hline Saudi & 33 & 94.3 & 34 & 97.1 & \multirow{2}{*}{0.348} & \multirow{2}{*}{${ }^{\mathrm{FE}} \mathrm{p}=1.000$} \\
\hline Non-Saudi & 2 & 5.7 & 1 & 2.9 & & \\
\hline \multicolumn{7}{|l|}{ Gender } \\
\hline Male & 12 & 34.3 & 16 & 45.7 & \multirow{2}{*}{0.952} & \multirow{2}{*}{0.329} \\
\hline Female & 23 & 65.7 & 19 & 54.3 & & \\
\hline
\end{tabular}

American Research Journal of Nursing

Page 5 
Effectiveness of Concept Map as Diabetic Foot Care Educational Intervention among Type 2 Diabetic Patients

\begin{tabular}{|c|c|c|c|c|c|c|}
\hline Marital Status & & & & & & \\
\hline Single & 29 & 82.9 & 31 & 88.6 & \multirow{4}{*}{3.211} & \multirow{4}{*}{${ }^{\mathrm{MC}} \mathrm{p}=0.486$} \\
\hline Married & 2 & 5.7 & 2 & 5.7 & & \\
\hline Divorced & 1 & 2.9 & 2 & 5.7 & & \\
\hline Widow & 3 & 8.6 & 0 & 0.0 & & \\
\hline \multicolumn{7}{|l|}{ Education Level } \\
\hline Illiterate & 5 & 14.3 & 8 & 22.9 & \multirow{4}{*}{3.915} & \multirow{4}{*}{0.271} \\
\hline Read and write & 11 & 31.4 & 12 & 34.3 & & \\
\hline Secondary & 13 & 37.1 & 6 & 17.1 & & \\
\hline Academic & 6 & 17.1 & 9 & 25.7 & & \\
\hline \multicolumn{7}{|l|}{ Occupation } \\
\hline Administrative & 11 & 31.4 & 8 & 22.9 & \multirow{5}{*}{2.739} & \multirow{5}{*}{${ }^{\mathrm{MC}} \mathrm{p}=0.678$} \\
\hline Elementary occupations & 2 & 5.7 & 1 & 2.9 & & \\
\hline Clerical support workers & 0 & 0.0 & 2 & 5.7 & & \\
\hline Unemployed & 20 & 57.1 & 22 & 62.9 & & \\
\hline Retired & 2 & 5.7 & 2 & 5.7 & & \\
\hline \multicolumn{7}{|l|}{ Living place } \\
\hline Rural & 9 & 25.7 & 6 & 17.1 & \multirow{2}{*}{0.764} & \multirow{2}{*}{0.382} \\
\hline Urban & 26 & 74.3 & 29 & 82.9 & & \\
\hline \multicolumn{7}{|l|}{ Family history of DM } \\
\hline Yes & 30 & 85.7 & 32 & 91.4 & \multirow{2}{*}{0.565} & \multirow{2}{*}{${ }^{\mathrm{FE}} \mathrm{p}=0.710$} \\
\hline No & 5 & 14.3 & 3 & 8.6 & & \\
\hline \multicolumn{7}{|l|}{ Duration of DM } \\
\hline$<5$ years & 14 & 40.0 & 13 & 37.1 & \multirow{4}{*}{1.454} & \multirow{4}{*}{${ }^{\mathrm{MC}} \mathrm{p}=0.772$} \\
\hline $5-<10$ years & 12 & 34.3 & 15 & 42.9 & & \\
\hline $10-<20$ years & 7 & 20.0 & 4 & 11.4 & & \\
\hline$\geq 20$ years and over & 2 & 5.7 & 3 & 8.6 & & \\
\hline
\end{tabular}

\begin{tabular}{|c|c|c|c|c|c|c|}
\hline \multirow{2}{*}{ Socio demographic data } & \multicolumn{2}{|c|}{ Study $(n=35)$} & \multicolumn{2}{|c|}{ Control(n=35) } & \multirow{2}{*}{$\chi^{2}$} & \multirow{2}{*}{$\mathbf{p}$} \\
\hline & No. & $\%$ & No. & $\%$ & & \\
\hline \multicolumn{7}{|l|}{\begin{tabular}{|l} 
Follow up with podiatrist clinic \\
\end{tabular}} \\
\hline Yes & 3 & 8.6 & 1 & 2.9 & \multirow{2}{*}{1.061} & \multirow{2}{*}{${ }^{\mathrm{FE}} \mathrm{p}=0.614$} \\
\hline No & 32 & 91.4 & 34 & 97.1 & & \\
\hline \multicolumn{7}{|c|}{ Often do you follow up with podiatrist clinic } \\
\hline Once a week & 0 & 0.0 & 0 & 0.0 & \multirow{4}{*}{1.406} & \multirow{4}{*}{${ }^{\mathrm{MC}} \mathrm{p}=0.615$} \\
\hline Once a month & 1 & 2.9 & 0 & 0.0 & & \\
\hline Once a year & 2 & 5.7 & 1 & 2.9 & & \\
\hline Never & 32 & 91.4 & 34 & 97.1 & & \\
\hline \multicolumn{7}{|c|}{ Receive health education about foot care } \\
\hline No & 30 & 85.7 & 33 & 94.3 & \multirow{2}{*}{1.429} & \multirow{2}{*}{${ }^{\mathrm{FE}} \mathrm{p}=0.428$} \\
\hline Yes & 5 & 14.3 & 2 & 5.7 & & \\
\hline
\end{tabular}


Effectiveness of Concept Map as Diabetic Foot Care Educational Intervention among Type 2 Diabetic Patients

\begin{tabular}{|l|c|c|c|c|c|c|}
\hline \hline Teaches you about foot care $(\mathbf{n}=\mathbf{7})$ & \multicolumn{2}{|c|}{$(\mathbf{n}=\mathbf{5})$} & \multicolumn{2}{|c|}{ (n= 2) } & & \\
\hline Doctor & 0 & 0.0 & 1 & 50.0 & & \\
\hline Podiatrist clinic & 1 & 20.0 & 0 & 0.0 & & \\
\hline Diabetic education nurse & 2 & 40.0 & 0 & 0.0 & \multirow{3}{*}{6.099} & \multirow{2}{*}{${ }^{\mathrm{N}} \mathrm{p}=0.533$} \\
\hline Family & 1 & 20.0 & 0 & 0.0 & \\
\hline Friends & 1 & 20.0 & 0 & 0.0 & & \\
\hline Doctor \& Diabetic education nurse & 0 & 0.0 & 1 & 50.0 & & \\
\hline
\end{tabular}

Table2. Comparison between the study and control group before and after intervention according to foot care self-efficacy scale $(n=70)$

\begin{tabular}{|c|c|c|c|c|c|c|c|c|}
\hline \multirow[b]{2}{*}{$\begin{array}{l}\text { Foot care self- } \\
\text { efficacy scale }\end{array}$} & \multicolumn{2}{|c|}{ Before } & \multirow[b]{2}{*}{$\mathbf{t}$} & \multirow[b]{2}{*}{$\mathbf{p}$} & \multicolumn{2}{|c|}{ After } & \multirow[b]{2}{*}{$\mathbf{t}$} & \multirow[b]{2}{*}{$\mathbf{p}$} \\
\hline & $\begin{array}{l}\text { Study Group } \\
\quad(n=35)\end{array}$ & $\begin{array}{c}\text { Contro Group } \\
(n=35)\end{array}$ & & & $\begin{array}{c}\text { Study Group } \\
(n=35)\end{array}$ & $\begin{array}{c}\text { Control Group } \\
(n=35)\end{array}$ & & \\
\hline \multicolumn{7}{|l|}{ Total score } & \multirow{6}{*}{7.096} & \multirow{6}{*}{$<0.001$} \\
\hline Min. - Max. & $13.0-60.0$ & $13.0-59.0$ & \multirow{5}{*}{0.317} & \multirow{5}{*}{0.752} & $48.0-60.0$ & $13.0-59.0$ & & \\
\hline Mean \pm SD & $36.97 \pm 11.44$ & $37.89 \pm 12.68$ & & & $55.03 \pm 2.72$ & $40.23 \pm 12.04$ & & \\
\hline \multicolumn{3}{|l|}{$\%$ score } & & & & & & \\
\hline Min. - Max. & $2.08-100.0$ & $2.08-97.92$ & & & $75.0-100.0$ & $2.08-97.92$ & & \\
\hline Mean \pm SD & $52.02 \pm 23.84$ & $53.93 \pm 26.41$ & & & $89.64 \pm 5.66$ & $58.81 \pm 25.08$ & & \\
\hline
\end{tabular}

Table3. Comparison between the study and control group before and after intervention according to foot care behavior $(n=70)$

\begin{tabular}{|c|c|c|c|c|c|c|c|c|}
\hline \multirow[b]{2}{*}{$\begin{array}{l}\text { Foot care } \\
\text { behavior }\end{array}$} & \multicolumn{2}{|c|}{ Before } & \multirow[b]{2}{*}{$\mathbf{t}$} & \multirow[b]{2}{*}{$\mathbf{p}$} & \multicolumn{2}{|c|}{ After } & \multirow[b]{2}{*}{$\mathbf{t}$} & \multirow[b]{2}{*}{$\mathbf{p}$} \\
\hline & $\begin{array}{c}\text { Study Group } \\
(n=35)\end{array}$ & $\begin{array}{c}\text { Control Group } \\
(n=35)\end{array}$ & & & $\begin{array}{c}\text { Study Group } \\
(\mathrm{n}=35)\end{array}$ & $\begin{array}{c}\text { Control Group } \\
(n=35)\end{array}$ & & \\
\hline \multicolumn{7}{|l|}{ Total score } & \multirow{6}{*}{8.683} & \multirow{6}{*}{$<0.001$} \\
\hline Min. - Max. & 28.072 .0 & $23.0-65.0$ & \multirow{5}{*}{0.193} & \multirow{5}{*}{0.848} & $53.0-76.0$ & $23.0-70.0$ & & \\
\hline Mean \pm SD & $47.97 \pm 11.04$ & $47.43 \pm 12.51$ & & & $69.31 \pm 4.33$ & $50.09 \pm 12.37$ & & \\
\hline \% score & & & & & & & & \\
\hline Min. - Max. & $35.90-92.31$ & $29.49-83.33$ & & & $67.95-97.44$ & $29.49-89.74$ & & \\
\hline Mean \pm SD & $61.50 \pm 14.15$ & $60.81 \pm 16.04$ & & & $88.86 \pm 5.55$ & $64.21 \pm 15.85$ & & \\
\hline
\end{tabular}

\section{DISCUSSION}

Diabetic patients have been increasing over the years and many factors like lack of education, lack of access to proper health care centres and also poor diet habits. Diabetic patients usually face several complications like low blood sugar, sweating, feeling sleepy, confusion and hunger, trouble speaking, dizziness, feeling weak and nervous and even passing out. High blood sugar levels can also be caused by diabetes, where a patient will experience poor vision, blurred vision, weight loss, headache, nerve damage and even frequent urination.

Diabetic Foot ulcers are very common serious and costly complication of diabetes proceeding of amputation. The number of diabetic patients with foot ulcers is increasing in the middle age group. Diabetic patients with a long duration of diabetic mellitus and poor blood sugar control have become co-morbidities of diabetes. One 
of the most major causes of diabetic foot ulcer is patient lack of knowledge about foot care. Education to the patients, and to significant others and people in the community on diabetes and diabetic foot care can reduce the risk of foot ulcer subsequently amputations. The health care personnel, medical and nursing personnel should screen the patients in the primary level in order to prevent diabetic foot ulcer.Foot care practice is one of the major ways for preventing diabetes foot ulcer among diabetes patients. Therefore,Concept map tool can be used to educate and emphasize importance of foot care practice, at home and at the hospitals and also educating patients on the several ways to care for their feet and how to check for any signs of nerve damage and soreness ${ }^{10}$.

In this study findings discussed about the of the socio demographic data revealed that diabetic mellitus affect the people with increasing age, sex, nationality, educational level, occupation, living place, family history of diabetes, duration of diabetes, follow up with podiatrist clinic, often follow up with podiatrist clinic and health education about diabetic foot care. The economic burden on the diabetic patients need to be eliminated. There is urgent need for education about the management and prevention of diabetes and diabetic foot ulcer among patients.

In this study findings reported that the one third $(37,1 \%)$ of diabetic patients participated in the sample were aged between 40-50 in the study group while the control group above 50 years are around half (45.7\%). This could be because type 2 diabetes patient was used as an estimate risk at this age group. This finding is congruent with studies conducted by Funnel and Brown (2011) people who are diagnosed with type 2 diabetes are commonly aged above 40 . Type 2 diabetes is associated with inadequate insulin or the insulin produced does not function properly. This type of diabetes can be controlled by having a controlled diet in the form of a balanced diet, weight loss and perspective exercises. Insulin injections can also be used as a form of therapy. Similarly, conducted a study and reported that diabetes is more common in the age group of 45- 50 years but apparently, cases have seen it increasing within adolescents too. However, there has been an increase in genetic makers which has been associated with type 1 diabetes. Type 2 diabetes has been considered to be familial but apparently there are certain genes which have been associated with a higher risk of type 2 diabetes among some individuals. These two types of diabetes are complex chronic diseases emanating from gene mutations and other considerable environmental factors. ${ }^{11}$

In this study findings sought to determine the effectiveness of concept map education on foot care self-efficacy and behaviour among patients with diabetic between the control and experimental group. The relevant data was collected from the both groups. The study findings revealed that the foot care self-efficacy scale showed significant difference between the study and control group after the intervention. According to the current study, foot care is a crucial step when treating or preventing diabetes mellitus from spreading to the foot of the patient. It is clear that the manifestation of wounds on the feet is one of the signature symptoms that a patient has not been taking care of their feet.

The study findings were supported by Robert Foot ulcers are significant complications of diabetes mellitus and lead to need appropriate management. Prevention is better than cure. Preventing the causes are neuropathy, trauma, deformity, high plantar pressures and peripheral arterial diseases ${ }^{12}$. The Bates Jensen wound assessment tool is the one helps in categorizing the wound and its characteristics. The initial treatment off pressure measures are total contact casts, removable cast walker or half shoes. Sharp debridement and management of underlying infection and ischemia are also critical in care of foot ulcers. Prompt and aggressive treatment of diabetic foot ulcers can prevent amputations. The recent study depicted that concept mapping is one of the best interventions that can be used to address the issue of foot ulceration. One of the main roles of the concept mapping was the ability to detect the foot ulceration, earlier before it causes more effects ${ }^{13}$.

The current study reported that more than two third of the study group after using the concept map as educational 
Effectiveness of Concept Map as Diabetic Foot Care Educational Intervention among Type 2 Diabetic Patients

intervention was $(65,7 \%)$ while the control group only $(31,4 \%)$, patient stated that strongly confident about "If I was told to do so, I can wear shoes and socks every time, on the other hand the current study revealed that two third of the study group after using the concept map as educational intervention was (60\%) while the control group only (34,3\%), patient stated that strongly confident about "After washing my feet I can dry between my toes "A good number of patients learned through using of concept mapping the importance of dryness between their toes.

The study findings are consistent with the study conducted by Bartolo, Mizzi, \& Formosa, (2013) reported about the management of foot care and he stated that the feet should have cleaned and dried at least once a day especially in the inter-digital spaces between the toes. The water used for rinsing the foot must be less than 37 centigrade. Typically, it is recommended to use the forearm to assess the temperature. This technique aids in preventing burning of the extremities due to the glove stocking neuropathy nature in patients who have diabetes it is also crucial to inspect the inner soles of the shoes before wearing them. ${ }^{14}$

Present study demonstrated that some of the most common symptoms of foot ulceration among individuals with diabetes mellitus include the discoloration of the skin, blisters on the foot, red streaks, tingling in the foot, stains appearing on socks, deformed feet, and changes in the temperature of the skin ${ }^{15}$.However, it is also apparent that not all these symptoms would be manifested in an individual at once. Various factors such as the stage of development of the diabetes, the health of the individual, and the lifestyle of the individual are instrumental in determining the nature of symptoms that an individual would experience. The stage of the foot ulceration is also essential in determining the symptoms that would be manifested. The most essential thing is for individuals to ensure that they notice these changes and take action before it is too late. Hence it can be concluded that there was effectiveness in the concept map education in improving the knowledge of study group.

The present study demonstrated that behaviour the current study revealed the majority of the study group after using the concept map as educational intervention was $(97,1 \%)$ while the control group $(65,7 \%)$, patient answered that (never ) about "Do you put your feet near the fire". That we are not need to warm the feet because the atmosphere stable for living. The study findings are consistent with Miller et al. (2014) agrees with this finding stating that patients with diabetes mellitus have sensitive feet that need special care and therefore, they will rarely put their feet near fires to protect them ${ }^{16,17}$.

The present study also proposed the use of concept mapping as a patient-cantered approach towards educating nurses and patients on proper foot care practices and the importance of regular inspection of feet This is one of the advantages of using concept mapping as an intervention in addressing the issue of foot care for diabetes patients. Diabetes patients are required to always take special care of their feet because the high blood sugar levels may cause nerve damage on the feet and circulation difficulties which is bad for their feet. They are required to have their feet checked regularly to notice any signs of sores, wounds or ingrown toenails so that they can be treated early enough.

The present study also depicts that the concept maps also enables practitioners to determine the strategies that can be used to prevent foot ulcerations. Prevention is always a better option especially when individuals are dealing with lifestyle diseases such as diabetes. The management of diabetes is one of the biggest challenges in an individual's health. Therefore, it would be essential to prevent the other factors that would cause further health complications such as foot ulcers. Identifying preventive strategies enables the practitioners and the patients to avoid the issue of foot ulcerations. However, the study shows that a concept map must be broader than the normal map in order to reflect issues such as preventive strategies that can be used to avoid the ulcerations. 
Effectiveness of Concept Map as Diabetic Foot Care Educational Intervention among Type 2 Diabetic Patients

There are some limitations in the current study and it was conducted in single hospital, and therefore results may not apply to all the other hospitals because of the different work dynamics. The sample used to conduct this study was sourced from one place therefore not that conclusive and duration of the intervention is limited for four weeks. In future prospective interventional study can be conducted focused.

\section{CONCLUSION}

The present study finding implies based on the provisions of the studies, it is appropriate to ascertain that concept maps play a significant role in addressing the issue of education on proper foot care practices among diabetes patients. The lack of awareness among diabetes patients causes a lot of damage to their feet and eventually mental health. However, it is apparent that the use of concept maps helps to identify some of the most effective strategies that can be used in the maintaining of healthy feet and preventing bruises and cuts and sores. Concept maps help nurses to improve in critical thinking in providing education on foot care and also advising patients on at-home foot care. This makes it easier for the patient and the practitioner to avoid any foot complications and ensure maintenance of healthy feet. Hence the study clearly depicts the importance of concept maps in educating patients with diabetes on importance of foot care.

\section{ACKNOWLEDGMENT}

Researchers thank all the participants for their valuable contribution.

\section{REFERENCES}

1. The world health Organization report on diabetes 2016.

2. Shaw, J. E., Sicree, R. A.,\&Zimmet, P. Z. (2010). Global estimates of the prevalence of diabetes for 2010 and 2030. Diabetes Research and Clinical Practice 87 (1), 4-14.

3. Al-Rubeaan, K., Almashouq, M. K., Youssef, A. M., Al-Qumaidi, H., Al Derwish, M., Ouizi, S., ... \&Masoodi, S. N. (2017). All-cause mortality among diabetic foot patients and related risk factors in Saudi Arabia. PloS one, 12(11), 1-7

4. Alotaibi, A., Perry, L., Gholizadeh, L., \& Al-Ganmi, A. (2017). Incidence and prevalence rates of diabetes mellitus in Saudi Arabia: An overview. Journal of epidemiology and global health, 7(4), 211-218

5. Cavanagh, P. R., Lipsky, B. A., Bradbury, A. W., \&Botek, G. (2015). Treatment for diabetic foot ulcers. The Lancet, 366(9498), 1725-1735.

6. Dangol.N. (2015). Nurses' Role in the Prevention of Diabetic Foot Ulcer (DFU).29(3),80-84.

7. Formosa, C., Gatt, A., \&Chockalingam, N. (2016). A critical evaluation of existing diabetic foot screening guidelines. The review of diabetic studies: RDS 13(2-3), 158.

8. Hörnsten Å, Stenlund H, Lundman B, Sandström H. (2010). Improvements in HbA1c remain after 5 years-a follow up of an educational intervention focusing on patients' understandings of type 2 diabetes. Diabetes Research and Clinical Practice; 81(1), 50-5.

9. Polit, D. F., \& Beck, C. T. (2010). Essentials of nursing research: Appraising evidence for nursing practice: Lippincott Williams \& Wilkins.

10. Algshanen, M. A., Almuhanna, M. F., Almuhanna, A. M., Alghobaish, F. F., Alajji, N. A., Alabdullah, H. J., ... \&Almustafa, M. A. (2017). Diabetic Foot Awareness among Diabetic Patients in Saudi Arabia. Egyptian Journal of Hospital Medicine, 68(2), 1289-1290 . 
Effectiveness of Concept Map as Diabetic Foot Care Educational Intervention among Type 2 Diabetic Patients

11. Riegel, B., Moser, D. K., Buck, H. G., Dickson, V. V., Dunbar, S. B., Lee, C. S., ... \& Webber, D. E. (2017). Self-Care for the Prevention and Management of Cardiovascular Disease and Stroke: A Scientific Statement for Healthcare Professionals From the American Heart Association. Journal of the American Heart Association 6(9), 11-12.

12. Hu, L.-T., \&Bentler, P. M. (2011). Cutoff criteria for fit indexes incovariance structure analysis: Conventional criteria versus new alternatives. Structural Equation Modelling 6(1), 1-55.

13. Khandan M, Noohi E, Mirzazadeh A. (2010). Effect of electronic self-care education and applying continues care on practice in type 2 diabetic patients; a randomized clinical trial. Journal of Kermanshah University of Medical Sciences 2012; 15(6),1-10.

14. Nemcová, J., \&Hlinková, E. (2014). The efficacy of diabetic foot care education. Journal of clinical nursing 23(5-6), 877-882.

15. Khandan M, Noohi E, Mirzazadeh A. (2010). Effect of electronic self-care education and applying continues care on practice in type 2 diabetic patients; a randomized clinical trial. Journal of Kermanshah University of Medical Sciences 2012; 15(6),1-10

16. Miller J. D., Carter E., Shih J., Giovinco N. A., Boulton A. J., Mills J. L., Armstrong D. G. (2014). How to do a 3-minute diabetic foot exam: This brief exam will help you to detect major risks quickly and prompt you to refer patients to appropriate specialists. Journal of Family Practice 63(11), 646-654

17. Duke SA, Colagiuri S, Colagiuri R. (2011). Individual patient education for people with type 2 diabetes mellitus. The Cochrane Library 10(1),1.

18. Grant T, Soriano Y, Marantz PR, Nelson I, Williams E, Ramirez D, et al. (2014). Community-based screening for cardiovascular disease and diabetes using HbA1c. American Journal of Preventive Medicine 26(4), 271-5.

Citation: Reem Mohammad AL Johani, Aida Elgamil, Elham Abduallah Al Nagshabandi, "Effectiveness of Concept Map as Diabetic Foot Care Educational Intervention among Type 2 Diabetic Patients". American Research Journal of Nursing. 2019; 5(1): 1-11.

Copyright (c) 2019 Reem Mohammad AL Johani, Aida Elgamil, Elham Abduallah Al Nagshabandi, This is an open access article distributed under the Creative Commons Attribution License, which permits unrestricted use, distribution, and reproduction in any medium, provided the original work is properly cited. 